\title{
Vitriolage: A Case of a 19-Year-Old Girl
}

\author{
Mohammad Jubaidul Kabir ${ }^{1}$, Palash Kumar Bose ${ }^{2}$, Farhana Salam ${ }^{3}$ \\ Received: November 11, 2015 Accepted: December 27, 2015 \\ doi: http://dx.doi.org/10.3329/jemc.v6i1.26382
}

\begin{abstract}
Acid throwing, also called an acid attack or vitriolage, is a form of violent assault. It is defined as the act of throwing strong corrosive on the body of a person "with the intention of injuring or disfiguring [them] out of jealousy or revenge". Here we present a case of a 19year-old girl who was victimized because she refused a love proposal. She was admitted in the One Stop Crisis Center (OCC) of Dhaka Medical College Hospital. Acid burn injuries involved whole of the right side of the face, front and adjacent right side of the neck, right shoulder and front of the right side of the chest. The burnt areas were wet with serous discharge. She was treated with intravenous fluid, antibacterial ointment on her affected area, her wounds were washed with plenty of water and sodium-bi-carbonate, antibacterial eye ointment was applied on her eyes, tetanus toxoid and analgesics were given.
\end{abstract}

Key words: Vitriolage; Assault; Victim; OCC

J Enam Med Col 2016; 6(1): 47-50

\section{Introduction}

Vitriolage means the throwing of any corrosive, not necessarily sulphuric acid, on a person with malicious intent. These fluids are usually thrown on the face with the intention of destroying vision or causing facial disfigurement and this results in grievous hurt. Sulphuric acid (oil of vitriol) is most commonly used for this purpose and hence it is called vitriolage. Nitric and carbolic acids are sometimes used. Sometimes caustic soda and caustic potash are also used. Sulphuric acid produces severe chemical burn. ${ }^{1}$ This crime has its origin in quarrels between workmen and masters over wages in Glasgow during the early part of the $19^{\text {th }}$ century. Its frequency led to legislative action. The crime belongs under the offence against the persons act 1861 S29 and it is punishable at the discretion of court by imprisonment for life or death sentence. Violence against women is a universal phenomenon but its manifestation differs from one society to another. Violence against women within South Asia includes rape and sexual abuse, trafficking, prostitution, domestic violence, psychological abuse etc. Acid throwing is an extreme form of violence. The alarming rise in its frequency is a cause of concern. Although one particular region in Bangladesh has been identified as being especially prone to this form of violence, more case of acid attacks have been around central Bangladesh. Acid is a corrosive substance that can burn holes in wood and corrode metals. It has various applications, primarily industrial. In our country vitriolage was once rampant especially upon young girls and women. Fortunately, the incidence decreased considerably after imposing the death sentence for that offence. But recent rise on the incidence of vitriolage is again noticed. Acid throwing has also occurred in the USA. The usual target is the face of the victim to permanently disfigure her face. This may lead to the destruction of the eyes with permanent loss of sight. The motive for vitriolage is jealousy, disappointment in love, taking revenge etc.

1. Associate Professor, Department of Forensic Medicine, Monno Medical College, Manikgonj

2. Assistant Professor, Department of Forensic Medicine, Enam Medical College, Savar, Dhaka

3. Assistant Professor, Department of Forensic Medicine, Green Life Medical College, Dhaka

Correspondence Mohammad Jubaidul Kabir, Email: jubaidul.kabir@yahoo.com 


\section{Case report}

The victim is a 19-year-old girl from Ti-Ti para, Narayangonj. Permission was taken from the concerned authority before interviewing the victim. According to the statement of the victim, she used to work in a house as a maid servant situated near Narayangonj. She belongs to a lower class family, so she did this job to support her family and also studied in a local NGO school. A young man of her locality proposed her for love and he used to disturb her while she was out for work. She did not respond and rejected him. She also told about this to her parents who called that young man and scolded him. But the man continued to offer her love. He also gave marriage proposal to her parents, but they rejected. This enraged him and he threw acid on her through window at night while she was staying in lying posture in her house. She felt some sticky liquid trickle down her face. She felt intense pain and screamed. The neighborers immediately took her to Narayangonj Sadar Hospital. After washing the affected area with plenty of soap and water, the doctor advised her to get admitted in Dhaka Medical College Hospital and accordingly she was admitted in One Stop Crisis Center (OCC) of the hospital for treatment and legal, lawyer and counselor support.

On examination, there were signs of splashing and trickling down of the acid on the body. The injuries were as follows:

1. A burnt area on the right side of the face involving the right side of the forehead, front and sides of left cheek up to the chin covering an area of 6 inches $x$ 3 inches. Right upper eyelid was injured but eye ball was not affected; vision was intact.

2. A burnt area on the right side of the neck over the front and adjacent lateral side covering area of 5 inches $\times 3$ inches. Upper margin was continuous with the burn on the cheek and the lower margin was gradually tapering to an angle 3 inches below the suprasternal notch. Over the front of the chest was a trickling mark.

3. A burn 3 inches $\times 2$ inches over the upper anterior and adjacent lateral part of the right shoulder. Its lower edge ended into a tapering over the front of the right side of the chest. The lower end of the burn was 2 inches above the left nipple and 2 and $1 / 2$ inches lateral to the midline.
4. A burn 3 inches $\times 1$ inch almost triangular in shape over the upper and posterior part of the right shoulder. Its lowest point was situated 3 inches to the right of the midline and 2 inches above the inferior angle of the left scapula.

The total burnt area was about $20 \%$ of the total body surface. The burnt area was sharply demarcated from the healthy skin. The margins were red and inflammed and the skin over the affected part was black in color.

The burnt areas were washed with plenty of water, normal saline and sodium-bi-carbonate solution followed by application of antibacterial ointment to the affected skin, antibiotic eye ointment, intramuscular tetanus toxoid and oral antibiotic therapy.

\section{Discussion}

The term vitriolage literally means throwing of the oil of vitriol on the body of a person with the intention to cause bodily injury. But for practical purpose this term is used in all cases of throwing of any corrosive agent on the body of a person. The usual target is the face of the victim with the idea to cause disfiguration of the face. This may lead to destruction of the eyes with permanent loss of eyesight. There is ulceration and resultant scar formation of the contaminated area of the body. Due to damage of the nerve endings these are comparatively painless lesions. Wide area of the body may be involved with evidence of spilling or splashing or pouring acid. These injuries heal with scar formation and thus cause permanent disfiguration, loss of eye sight and contracture. Thus if the victim survives with any such outcomes, the act of vitriolage may amount to the causation of grievous hurt. ${ }^{2}$ Death may result from shock and toxemia if extensive area is involved.

The patient was complaining of pain over the burnt area. Acid burn injuries involved whole of the right side of the face, front and adjacent right side of the neck, right shoulder and front of the right side of the chest. The burnt areas were wet with serous discharge. There were signs of splashing and trickling down of the acid on the body. The most notable effect of acid attack is the lifelong disfigurement. According to the Acid Survivors' Foundation in Pakistan, there is a high survival rate amongst victims of acid attacks. Consequently the victim is faced with physical challenge, which requires long term surgical treatment, 
as well as psychological challenge, which requires in depth intervention from psychologists and counselors at each stage of physical recovery. ${ }^{3}$ These far-reaching effects on their lives impact their psychological, social and economic viability in communities. The medical effects of acid throwing are extensive. As a majority of acid throwing is aimed at the face ${ }^{4}$, severity of the damage depends on the concentration of the acid and the period of time before the acid is thoroughly washed off with water or neutralized with a neutralizing agent. The acid can rapidly eat away skin, the layer of fat beneath the skin and in some cases even the underlying bone. Eyelids and lips may be completely destroyed. The nose and ears are severely damaged. ${ }^{5}$ The skull may be partly destroyed or deformed and hair may be lost. Ear cartilage is usually partly or totally destroyed, deafness may occur. Eyelids may be burned off or deformed, leaving the eyes extremely dry and prone to blindness. Acid directly in the eye also damages sight, sometimes causes blindness of both eyes. Nose can be shrunken and deformed; the nostrils may close off completely due to destroyed cartilage. The mouth may become shrunken and narrow, and it may lose its full range of motion. Sometimes the lips may be partially or totally destroyed, exposing the teeth. Eating can become difficult. Scars can run down from chin to neck area, shrinking the skin and extremely limiting range of motion of neck. Inhalation of acid vapor usually creates respiratory problems and exacerbates restricted airway pathways in acid victims. In addition to the medical effects, acid victims also face the possibility of septicemia, renal failure, skin depigmentation and even death. In addition to medical and psychological effects, many social implications exist for acid survivors specially women. For example, such attacks usually leave victims handicapped in some way, rendering them dependent on either their spouse or family for everyday activities, such as eating and running errands. This dependency is increased by the fact that acid survivors are unable to find work, due to impaired vision and range of motion. This negatively impacts their economic viability, causing hardship in the families that take care of them. As a result divorce rates are high. Abandonment by husbands was found in $25 \%$ acid cases in Uganda. ${ }^{6}$ Moreover, acid survivors who are single when attacked almost certainly become ostracized from society, usually ruining marriage prospects.

\section{Bangladesh situation}

In Bangladesh, where such attacks are relatively common, these are mostly a form of domestic violence. Bangladesh has the highest reported incidence of acid assaults in the world. ${ }^{4}$ According to Acid Survivors' Foundation in Bangladesh, the country has reported 3242 acid attack victims during 1999 to 2014, with the highest 494 victims in 2002. Rates have been steadily decreasing by $15-20 \%$ since 2002. In Bangladesh acid throwing shows high gender discrimination, with one study citing a male to female victim ratio of $1: 2$ and $52 \%$ of acid attack survivors in Bangladesh are women. ${ }^{7}$ Younger women are specially vulnerable to attack, with a recent study showing that $55 \%$ of acid assault survivors are within 35 years. $^{7}$ It is a relatively recent form of violence, with the earliest record in Bangladesh from 1983. Acid throwing is often referred to as crime of passion fueled by jealousy and revenge. ${ }^{4}$ Such passion is usually rooted in marriage and relationship. In 2014 a study showed, five were victims of acid assaults in dowry case, three victims were abused from husband/family related members, 32 were due to property dispute and eight victims were for refusal of sexual or romantic advances. Additionally the use of acid throwing in dowry arguments has been reported in Bangladesh. ${ }^{7}$ The chemical agents most commonly used to commit these attacks are hydrochloric acid and sulphuric acid. In 2002, Bangladesh introduced the death penalty for throwing acid and laws strictly controling the sale, use, storage and international trade of acids. The acids are used in traditional trades carving marble nameplates, coach bangles, goldsmiths, tanneries and other industries. The Acid Survivors' Foundation (ASF) is a Bangladeshi organization dedicated to raising awareness and preventing acid attacks and providing survivors with medical and legal aid. The foundation was founded by Dr. John Morrison OBE and subsidized by the British High Commission/British Women's Association in 1999 with substantial support from UNICEF and the Canadian International Development Agency. ASF initially began as service delivery organization. Currently, it is in the process of moving toward a right based development organization. ASF have subsequently been established in Uganda, Cambodia and Pakistan sustained by ASTI (Acid Survivors Trust International) also headed by Sir John Morrison.

Acid attack is a violent crime. The effects are so devastating that it could end a person's health, social life 
and economic conditions. As our country is fighting this crime with courage and implicating strict laws against it, we can hope that soon this country will be free from this crime. And those who were the victims of such assault should get the maximum support and sympathy from the society. The Government must help those victims with employment, medical and psychiatric treatment and rehabilitation. The society should help them and protest against such crime.

\section{References}

1. Reddy KSN. The essentials of forensic medicine \& toxicology. $31^{\text {st }}$ edn. India: Medical Book Coy, 2010: 296-297.

2 Nandy A. Principle of forensic medicine including toxicology. $3^{\text {rd }}$ edn. India: Central Book Agency, 2010: 517-518.

3. Knights B. Forensic pathology. $3^{\text {rd }}$ edn. India: Replica Press, 1996 (reprint 2013): 587.
4. Combating acid violence idea: Bangladesh, India \& Cambodia, from Avon foundation for women. Available at: http://www.acidviolence.org/uploads/files/Cambodia_CASC_ Situational_Analysis_Report_for_Media_FINAL_Nov2011. pdf. Accessed November 2015.

5. Combating Acid violence idea: Bangladesh, India \& Cambodia, from Avon foundation for women. Available at: http://www.ohchr.org/Documents/HRBodies/CEDAW/Harmf ulPractices/AvonGlobalCenterforWomenandJustice.pdf. Accessed November 2015.

6. "Acid attack in southeast Asia" by BBC news 2004. Available at:http://www.slate.com/articles/news_and_politics/ explainer/2013/02/history_of_acid_violence_when_did_peop le_start_throwing_vitriol.html. Accessed November 2015.

7. Acid Survivors' Foundation (ASF), Bangladesh. Available at: http://www.acidsurvivor.org/statistics. Accessed November 2015. 